\title{
Current State of Wilson Disease Patients in Central Japan
}

\author{
Yasuaki Tatsumi ${ }^{1}$, Ai Hattori ${ }^{1}$, Hisao Hayashi ${ }^{1}$, Jiro Ikoma ${ }^{2}$, Masahiko Kaito ${ }^{2}$, \\ Masami Imoto $^{3}$, Shinya Wakusawa ${ }^{4}$, Motoyoshi Yano ${ }^{5}$, Kazuhiko Hayashi ${ }^{6}$, \\ Yoshiaki Katano $^{6}$, Hidemi Goto ${ }^{6}$, Toshihide Okada $^{7}$ and Shuichi Kaneko ${ }^{7}$
}

\begin{abstract}
Objective This study evaluated the current state of patients with Wilson disease in central Japan.

Patients and Methods Between 1999 and 2007, 30 patients were diagnosed as having Wilson disease with an International Diagnostic Score of 4 or more. The phenotypes, genotypes and post-diagnostic courses of these patients were analyzed.

Results Twenty-six patients had ATP7B mutations responsible for Wilson disease. Four patients had a single mutant chromosome. There were 2 major mutations of $2333 \mathrm{G}>\mathrm{T}$ and $2871 \mathrm{delC}$ (40\%), and 6 novel mutations $(13 \%)$ in our patients. The first clinical manifestation was the hepatic form in 22 , neurological form in 5, and hemolysis in 3 patients. The hepatic form was diagnosed around the age of 13 years, followed by neurological complication with a time lag of 9 years. Thus, some patients, especially patients with the neurological form, did not undergo early diagnostic tests including ATP7B analysis. During the post-diagnosis period, 3 patients were hospitalized for recurrent liver disease, and 2 patients committed suicide. One female patient died from acute hepatic failure associated with encephalopathy after fertilization therapy, while 2 male patients recovered from encephalopathy-free, prolonged hepatic failure after noncompliance with drug therapy. The King's Scores for liver transplantation were below the cut-off in both cases.

Conclusion To minimize delayed diagnosis, ceruloplasmin determination and ATP7B analysis may be recommended to patients showing hepatic damage of unknown etiology. At gene diagnosis, appropriate management of patients including compliance education and emotional care to prevent suicide might be important.
\end{abstract}

Key words: ATP7B, copper chelation, hepatic failure, suicide

(Inter Med 49: 809-815, 2010)

(DOI: 10.2169/internalmedicine.49.2931)

\section{Introduction}

The introduction of penicillamine into practice brought a revolution in the treatment of Wilson disease (WD), which was first described by Dr. SA Kinnier Wilson as a fatal disorder of hepatolenticular degeneration $(1,2)$. For patients who are intolerant of penicillamine, either another copper chelating agent, trientine, or zinc replacement therapy is now available $(3,4)$. Therefore, WD is now considered a treatable copper toxicosis with a benign prognosis if diag- nosed at an early stage $(5,6)$. However, some patients may not be diagnosed until later stages when irreversible complications have already occurred. Another issue in WD has been acute onset hemolysis leading to a lethal form of subacute hepatitis. Under the critical condition of donor shortages in Japan, it is important to appropriately select liver transplantation for patients whose prognosis would otherwise be poor, but would be fairly improved even with heterozygous donors (7), and avoid needless surgery in patients with self-limiting acute hepatic failure. The new King's score for liver transplantation without encephalopathy should

\footnotetext{
${ }^{1}$ Department of Medicine, Aichi Gakuin University School of Pharmacy, Nagoya, ${ }^{2}$ Mie-Syokaki Clinic, Tsu, ${ }^{3}$ Department of Internal Medicine, KARIYA TOYOTA General Hospital, Kariya, ${ }^{4}$ Division of Medical Technology, Nagoya University School of Health Sciences, Nagoya, ${ }^{5}$ Department of Internal Medicine, Yokkaichi Municipal Hospital, Yokkaichi, ${ }^{6}$ Department of Gastroenterology, Nagoya University Graduate School of Medicine, Nagoya and ${ }^{7}$ Disease Control and Homeostasis, Kanazawa University Graduate School of Medical Science, Kanazawa Received for publication September 28, 2009; Accepted for publication January 6, 2010 Correspondence to Dr. Hisao Hayashi, hhayashi@pdc.agu.ac.jp
} 
Table 1. Clinical Features of Patients

\begin{tabular}{|c|c|c|c|c|c|}
\hline Clinical Form & Number* ${ }^{1}$ & Age $($ mean $+/-\mathrm{SD})$ & FK Rings $*^{4}$ & Liver Histology $*^{5}$ & Urinary $\mathrm{Cu}^{* 6}$ \\
\hline Hepatic & 22 & $13.3 \pm 5.3 *^{2}$ & $9 / 22$ & $14 / 22$ & $8 / 22$ \\
\hline symtomatic liver damage & 13 & $11.5 \pm 5.3$ & $2 / 13$ & 8/13 (4 CAH, 4 LC) & $5 / 13$ \\
\hline asymptomatic liver damage & 7 & $14.4 \pm 3.3$ & $5 / 7$ & 5/7 (2 CAH, 3 LC) & $1 / 7$ \\
\hline chronic liver failure & 2 & $21,22 *^{3}$ & $2 / 2$ & $1 / 2(\mathrm{LC})$ & $2 / 2$ \\
\hline Neurological & 5 & $21.8 \pm 9.2 *^{2}$ & $5 / 5$ & $2 / 5$ (2 LC) & $2 / 5$ \\
\hline Hemolytic & 3 & $6,12,17 *^{3}$ & $1 / 3$ & $2 / 3(2 \mathrm{LC})$ & $0 / 3$ \\
\hline \multicolumn{6}{|c|}{$\begin{array}{l}*^{1} \text { The number of male patients (20) differed from that of female patients }(10) \text { in central Japan }\left(\mathrm{p}<0.05 \text { on } \mathrm{X}^{2} \text { test). The clinical }\right. \\
\text { significance in a small number of patients may be negligible. }\end{array}$} \\
\hline \multicolumn{6}{|c|}{$\begin{array}{l}*^{2} \text { There was an age difference between patients with the hepatic form and neurological form }((\mathrm{p}<0.05 \text { on Student's } \mathrm{t} \text {-test }) \text {, which is } \\
\text { important since the latter is a late complication of Wilson disease. } \\
*^{3} \text { Age of each patient. }\end{array}$} \\
\hline \multicolumn{6}{|c|}{$\begin{array}{l}{ }^{4} \text { Kayser-Fleischer }(\mathrm{KF}) \text { rings were positive in all patients with the neurologic form, and their positivity increased in aged patients with } \\
\text { the hepatic form. }\end{array}$} \\
\hline \multicolumn{6}{|c|}{$\begin{array}{l}\text { Results of liver histology study } *^{5} \text { and amount of urinary copper output }{ }^{6} \text { were all compatible with the diagnostic criteria of Wilson } \\
\text { disease. }\end{array}$} \\
\hline
\end{tabular}

be tested in Japanese patients (8).

In 1993, 3 groups were involved in cloning a copper transporting ATPase in WD patients (9-11). The introduction of gene diagnosis was highly expected to provide a definitive diagnosis of pre-symptomatic patients or questionable cases. However, subsequent studies on autosomal recessive disorder demonstrated that some hundreds of ATP7B mutations responsible for WD were distributed worldwide and showed geographical characteristics $(9,12-19)$. Therefore, geographic information on mutations is important for genetic diagnosis nationwide. An inherent problem with gene diagnosis is that some patients have only one chromosome or even none showing ATP7B mutation, but definitive diagnosis using ATP7B could provide a benefit to patients and their family members (20). Therefore, it might be timely research to evaluate the state of WD patients at the age of gene diagnosis. To clarify the current concern, this study investigated WD patients whose pathogeneses were detected by ATP7B analysis at 2 university hospitals and their affiliated clinics in central Japan.

\section{Patients and Methods}

The study population consisted of patients diagnosed as having WD at University Hospitals of Nagoya and Kanazawa, and their affiliated clinics in central Japan between 1999 and 2007. The diagnostic parameters applied here included Kayser-Fleischer rings, neurological symptoms, hypoceruloplasminemia, increased hepatic copper concentration, increased urinary copper output and ATP7B mutations. After written informed consent was obtained from each patient, genomic DNA was extracted from peripheral blood leukocytes and amplified for all 21 exons of the ATP7B gene and analyzed by direct sequencing (19). The final diagnosis of WD was determined by a score of 4 or more on the International Criteria (IC) (20). In brief, the scoring system consists of 2 points for Kayser-Fleischer rings, 2 for neuro- logical symptoms, 1 or 2 for hypoceruloplasminemia, increased urinary copper output, and increased copper concentration in the liver, 4 for mutation causing WD on both chromosomes, and 1 for that on one chromosome. Gene analysis on ATP7B was performed according to the guidelines of Aichi Gakuin University School of Pharmacy, Ethics Committee. Follow-up study of patients included telephone interviews with patients and family members.

\section{Statistical analysis}

Data are expressed as mean \pm SD. Sex difference and ages of patients with the hepatic form and neurological form were assessed by $\mathrm{X}^{2}$ test and Student's t-test, respectively.

\section{Results}

\section{Clinical features and genotypes of patients}

A total of 30 patients were included in the study. Twenty patients were male, and 10 were female. There was a maledominant sex difference $(\mathrm{p}<0.05)$. Mean age of male patients was $15 \pm 7$, while that of female patients were $13 \pm 6$ years. Clinical features of 30 patients at diagnosis are summarized in Table 1. Phenotypes were classified into hepatic $(n=22)$, neurological $(n=5)$, and hemolytic $(n=3)$. The hepatic form was further subclassified into symptomatic liver disease, asymptomatic liver disease and chronic liver failure. In 13 patients, chronic biochemical liver damage was detected during some incidental symptomatic condition such as flu. Seven patients were asymptomatic when a sibling was found to have Wilson disease. Two patients had decompensated liver function when diagnosed. The ages of patients with the hepatic form were younger than those of patients with the neurologic form $(13 \pm 5$ vs. $22 \pm 9, \mathrm{p}<0.05)$. One patient demonstrated the hepatic form at 7 years of age, and then the neurologic form at 22 years after intermittent compliance. All patients were hypoceluroplasminemic; 29 pa- 
Table 2. Genotypes of Patients

\begin{tabular}{|l|l|l|}
\hline Genotypes & $\begin{array}{l}\text { Number of } \\
\text { Families }(\mathrm{n}=23)\end{array}$ & $\begin{array}{l}\text { Number of Patients } \\
(\mathrm{n}=30)\end{array}$ \\
\hline Homozygotes, consanguineous & 3 & 6 \\
\hline Homozygotes, non-consanguineous & 1 & 2 \\
\hline Compound heterozygotes & 15 & 18 \\
\hline Heterozygotes & 4 & 4 \\
\hline
\end{tabular}

All of the index patients were symptomatic, and there were no pre-symptomatic patients among their family members. There were no patients with Wilson disease free from ATP7B mutations in this study.

All 4 heterozygotes with a mutation in one chromosome showed remarkable hypoceruloplasminemia and liver pathology compatible with Wilson disease.

Table 3. Mutations in ATP7B Responsible for Wilson Disease

\begin{tabular}{|c|c|c|c|}
\hline Type of Mutation & Mutations & $\begin{array}{l}\text { Number of } \\
\text { Chromosomes }\end{array}$ & References \\
\hline Insertion/Delation & $453 \mathrm{delC}^{*^{1}}$ & 1 & 18 \\
\hline Insertion/Delation & $1947 \mathrm{delG}^{* 2}$ & 1 & \\
\hline Insertion/Delation & 2299insC & 1 & 14 \\
\hline Insertion/Delation & $2650 \operatorname{del} 3 *^{1}$ & 1 & 18 \\
\hline Insertion/Delation & $2871 \mathrm{delC}^{* 3}$ & 12 & 14 \\
\hline Splice site & $1708-5 \mathrm{~T}>\mathrm{G}$ & 6 & 12 \\
\hline Missense & $2307 \mathrm{G}>\mathrm{T}(\mathrm{Met} 769 \mathrm{Ile})^{* 1}$ & 1 & 18 \\
\hline Missense & $2332 \mathrm{C}>\mathrm{T}(\operatorname{Arg} 778 \operatorname{Trp})$ & 2 & 15 \\
\hline Missense & $2333 \mathrm{G}>\mathrm{T}($ Arg778Leu $) *^{3}$ & 12 & 13 \\
\hline Missense & $2621 \mathrm{C}>\mathrm{T}($ Ala874Val $)$ & 4 & 16 \\
\hline Missense & 2755C > G (Arg919Gly) & 2 & 16 \\
\hline Missense & 2975C>T (Pro992Leu) & 2 & 14 \\
\hline Missense & 3029A $>C(A s n 1010 S e r) *^{1}$ & 2 & 18 \\
\hline Missense & 3086C > T (Gly1029Ile) & 1 & 17 \\
\hline Missense & 3556G>A (Gly1186Ser) & 1 & 16 \\
\hline Missense & 3643G>T (Asp1215Tyr)*1 & 2 & 19 \\
\hline Missense & 3800A >C (Asp1267Ala) & 1 & 16 \\
\hline Missense & 3809A>G (Asn1270Ser) & 4 & 9 \\
\hline
\end{tabular}

$*^{1}$ Novel mutations found for the first time in central Japan.

$*^{2}$ A novel mutation reported for the first time in this study.

$*^{3}$ Two major mutations in our patients were $2333 \mathrm{G}>\mathrm{T}$ and $2871 \mathrm{delC}$.

tients had serum ceruloplasmin levels less than $10 \mathrm{mg} / \mathrm{mL}(2$ points in IC), while one was $11.6 \mathrm{mg} / \mathrm{dL}$ (one point in IC). Kayser-Fleischer rings were examined in all patients, and were positive ( 2 points in IC) in 15 patients $(50 \%)$. The test was positive in all patients with the neurologic form. Liver biopsy was obtained in 19 patients and was positive for copper stain in $100 \%$ (one point in IC). In 10 patients, urinary copper was determined as a diagnostic test for WD (one or 2 points in IC). The study did not include any patients with initial clinical features of subacute hepatitis, normoceruloplasminemia or normal liver histology.

The genotypes are summarized in Table 2. Eight patients were homozygous, and 18 were compound heterozygous for ATP7B mutations responsible for WD. Four patients were heterozygous for the mutation, but all showed remarkable hypoceruloplasminemia and copper accumulation in the liver compatible with WD, reaching a diagnostic score of 4 or more (20). There were neither pre-symptomatic patients, nor patients free from ATP7B mutations. Non-consanguinity was dominant as the genetic background of patients in central Japan. Two patients homozygous for a common mutation came from a non-consanguineous family.

\section{ATP7B mutations in central Japan}

Eighteen mutations of ATP7B responsible for WD were detected in 30 patients (Table 3). Six mutations (453delC, 1947delG, 2307G>T, 2650del3, 3029A>C, 3643G>T) were first identified in our patients. Five of these have already been reported elsewhere $(18,19)$, while one frameshift mutation first reported in the current study is 1947delG. A 12year-old female patient who was compound-heterozygous for the new mutation 1947delG and a domestic mutation 1975C $>$ T appeared with a self-limited hemolytic episode. Two major mutations in our patients were $2333 \mathrm{G}>\mathrm{T}$ and $2871 \mathrm{delC}$, each of these being $20 \%$ (12/60) of the chromosomes. 
Table 4. Clinical Features and King's Score for Liver Transplantation of Patients with Severe Sequelae during Follow Up Period

\begin{tabular}{|l|l|l|l|l|l|}
\hline & Case $1 *^{1}$ & Case 2 & Case 3 & Case 4 & Case 5 \\
\hline Age/Sex at Entry & $7 / \mathrm{F}$ & $17 / \mathrm{M}$ & $16 / \mathrm{M}$ & $19 / \mathrm{M}$ & $19 / \mathrm{M}$ \\
\hline Initial Form & hepatic & hemolytic & hepatic & neurologic & hepatic \\
\hline ATP7B-1 & $3800 \mathrm{~A}>\mathrm{C}$ & 2871 delC & $1708-5 \mathrm{~T}>\mathrm{G}$ & $2332 \mathrm{C}>\mathrm{T}$ & $3809 \mathrm{~A}>\mathrm{G}$ \\
\hline ATP7B-2 & $?$ & $3643 \mathrm{G}>\mathrm{T}$ & $1708-5 \mathrm{~T}>\mathrm{G}$ & $3029 \mathrm{~A}>\mathrm{C}$ & $?$ \\
\hline Age at Episode & 36 & 36 & 25 & 27 & 21 \\
\hline Episode & AHF & SPHF & SPHF & suicide & suicide \\
\hline Bilirubin $(\mathrm{mg} / \mathrm{dL})$ & $9.9(2)$ & $1.6(0)$ & $11.9(2)$ & & \\
\hline INR $[\mathrm{PT}]$ & 2.36 & 2.03 & $(3)$ & 2.50 & \\
& {$[38.0 \%]$} & {$[40.5 \%]$} & {$[30.1 \%]$} & & \\
\hline AST $(\mathrm{IU} / \mathrm{L})$ & $80(0)$ & $126(1)$ & $75(0)$ & & \\
\hline WBC $(/ \mu \mathrm{L})$ & $7700(1)$ & $7000(1)$ & $6000(0)$ & & \\
\hline Albumin $(\mathrm{g} / \mathrm{dL})$ & $2.5(2)$ & $2.8(2)$ & $2.6(2)$ & & \\
\hline Total Score & 8 & 7 & 8 & & \\
\hline
\end{tabular}

\footnotetext{
AHF; acute hepatic failure with encephalopathy, SPHF; sudden-onset prolonged hepatic failure, AST; aspartate aminotransferase INR [PT]; international normalization rate of prothrombin time .

${ }^{* 1}$ The female patient presented with encephalopathy and progressive hepatic failure. Therefore, King's Scoring System for liver transplantation without encephalopathy should not be applied in that case. Cut-off of the Score System was 11, but the Scores were 7 and 8 in Cases 2 and 3, respectively. Both patients recovered from acute onset hepatic failure after long-term medical treatment.
}

\section{Follow-up study}

Severe sequelae of our patients during follow-up from 5 to 20 years are summarized in Table 4 . Three patients demonstrated recurrences of hepatic failure, and 2 patients committed suicide. One of 3 patients with recurrent hepatic failure (Case 1) was associated with progressive encephalopathy, and died after one month. Two other patients (Cases 2 and 3) recovered from sudden-onset prolonged hepatic failure. The new King's scores for liver transplant in WD without encephalopathy (8) for Cases 2 and 3 were 7 and 8, respectively.

\section{Case 1}

A 36-year-old woman was admitted because of jaundice. After diagnosis of WD at 7 years old, she had received intermittent copper chelation. At the age of 22 years, finger tremors were noted and the neurological form of WD was diagnosed. For 6 years, she underwent zinc replacement therapy. As shown in Fig. 1, fertilization therapy had been initiated 2 years earlier and was associated with latent biochemical liver damage. When jaundice appeared, hormone therapy was discontinued with prompt reduction of alkaline phosphatase and gamma-glutamyl transpeptidase, but serum levels of bilirubin increased gradually, followed by progressive encephalopathy and coagulopathy. After one month of extensive medical treatment, she died from hepatic failure. Since her sterility might have been due to advanced liver failure, poor compliance with the initial treatment followed by administration of hepatotoxic agents may have been responsible for her death.

\section{Case 2}

A 36-year-old male patient with a 20-year history of treatment for WD was admitted because of malaise. There were no identifiable triggers of insulin-dependent diabetic condition, and the maintenance dose of $600 \mathrm{mg}$ penicillamine per day might be insufficient for a patient weighing $89 \mathrm{~kg}$. As shown in Fig. 2, the patient remained subicteric and hypoprothrombinemic for the subsequent 10 months while receiving insulin replacement and a daily dose of 1,200 mg penicillamine, and required albumin supplements to control ascites. Then, a turning point appeared when hemoglobin decreased to $6.4 \mathrm{~g} / \mathrm{dL}$ with $14 \mathrm{ng} / \mathrm{mL}$ serum ferritin. Albumin concentration and prothrombin time increased gradually during the 6-month recovery period.

\section{Case 3}

Chelation therapy with penicillamine was re-instituted in a 25-year-old male patient after a 5-year interruption. Four weeks later, the patient presented with anemia associated with severe jaundice. Duodenal ulcer was confirmed by fiberscopy. His clinical course after admission is shown in Fig. 3. Despite the prompt disappearance of jaundice, plasma prothrombin levels remained low at about $25 \%$ during the first 3 months of treatment for acute-onset liver failure. The second episode of anemia was the turning point, followed by the recovery of albumin and prothrombin concentrations. Serum ferritin levels decreased from 543 to 31 $\mathrm{ng} / \mathrm{mL}$ over an 8 -month period following the turning point. The mental states of Cases 2 and 3 remained normal throughout the treatment period. The time table of liver functions and iron parameters around the turning points of Cases 2 and 3 are summarized in Table 5. 


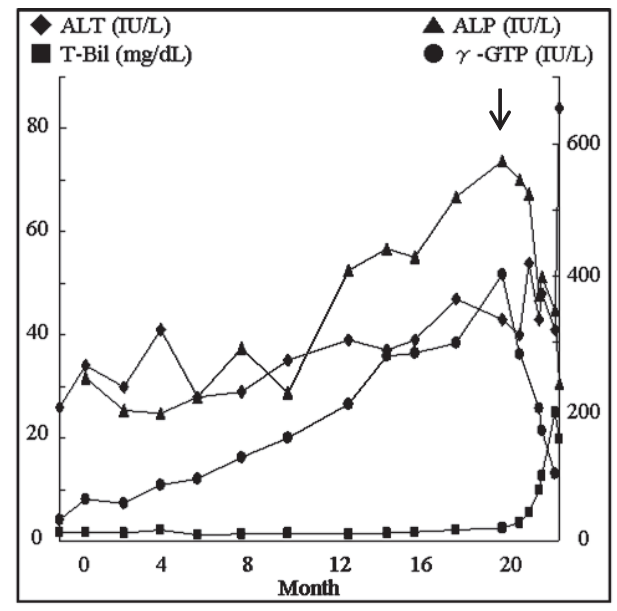

Figure 1. In Case 3, serum alanine aminotransferase (ALT), gamma glutamyl transpeptidase $(\gamma$ GTP) and alkaline phosphatase (ALP) increased gradually during fertilization therapy with steroid hormones, and jaundice appeared after 20 months of treatment (arrow). Discontinuation of the therapy was followed by prompt reduction of 3 serum parameters, but serum total bilirubin (T-Bil) levels increased rapidly with progressive coagulopathy and encephalopathy. The patient died one month thereafter.

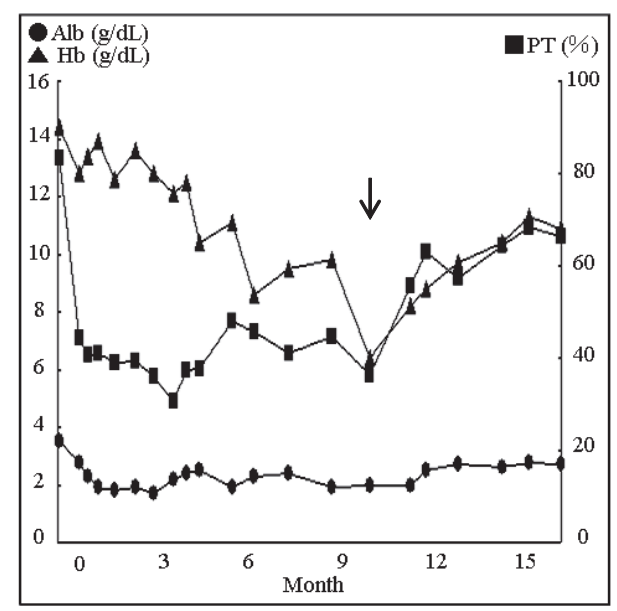

Figure 2. In Case 4, acute-onset liver failure with hypoprothrombinemia and hypoalbuminemia did not improve for the first 10 months. Then, a turning point appeared when iron deficiency induced severe anemia (arrow). Thereafter, protein synthesis represented by albumin concentration (Alb) and prothrombin time (PT) began to improve. The patient was slightly depressed, but serious hepatic encephalopathy did not appear throughout the clinical course.

\section{Case 4}

A 19-year-old man visited the clinic with gait and speech disturbance. Blood chemistry and the presence of KayserFleischer rings confirmed the clinical diagnosis of the neurological type of WD. Penicillamine therapy transiently improved extrapyramidal ataxia, but a few months later, severe dystonia suddenly appeared and restricted daily life thereafter. The final episode of periodic depression led him to sui-

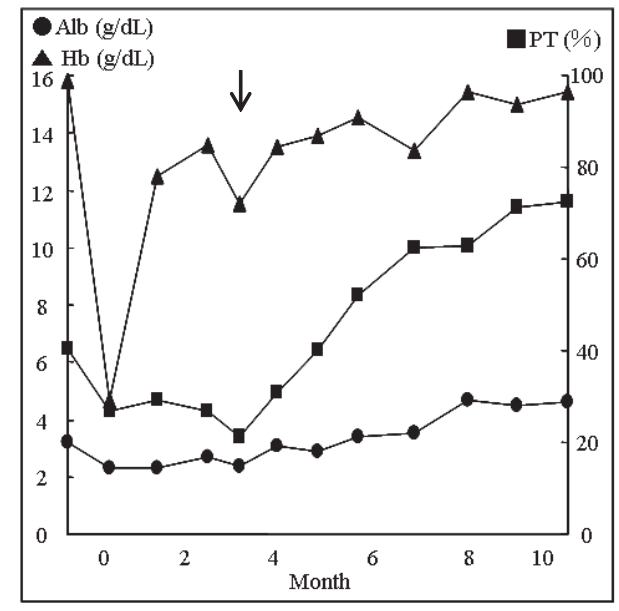

Figure 3. In Case 5, acute-onset liver failure with hypoprothrombinemia and hypoalbuminemia did not change for the first 3 months. Then, a decrease in hemoglobin (Hb) became the turning point for albumin concentration (Alb) and prothrombin time (PT) (arrow). As described in the text, the serum level of ferritin at the turning point was high in this case, but was finally decreased to a level of $31 \mathrm{ng} / \mathrm{mL}$. The mental state of this patient remained stable during the 10month treatment period.

cide at the age of 27 years.

\section{Case 5}

Another 19-year-old man was found to have hepatic WD. Penicillamine induced remarkable improvement of biochemical liver damage. Without any prodromal signs, the patient committed suicide at the age of 21 years.

\section{Discussion}

Patients with WD should be homozygous or compound heterozygous for disease-causing mutation in ATP7B gene, and hopefully their initial manifestation could be the hepatic form at pre-school age, provided that WD is due to autosomal recessive inheritance of impaired copper transporting ATPase in the liver. Disease-causing mutations were identified in 56 of 60 chromosomes in our patients (93.3\%). There is agreement that mutation analysis is incomplete in some patients with WD. This is likely due to technical problems in detecting mutations in ATP7B causing incomprehensible results with regard to autosomal recessive disorder. Genetic dysfunction of ATP7B might be involved in the posttranscriptional process as reported in other disorders (21). Even though new genes other than ATP7B have not yet been identified in patients with primary copper toxicosis (22), another possibility might be that candidate genes other than ATP7B are responsible for disease in these patients, as reported for non-HFE-hemochromatosis in hereditary hemochromatosis (23). One of the most common mutations in our patients was $2333 \mathrm{G}>\mathrm{T}$, which has also been reported by other institutes in Asia $(13,14)$. The other common mutation was 2871 delC, known as a major mutation in 
Table 5. Time Course of Liver Functions and Iron Indices in Cases 2 and 3

\begin{tabular}{|l|l|l|l|l|l|l|}
\hline & & $\begin{array}{l}\text { Bilirubin } \\
(\mathrm{mg} / \mathrm{dL})\end{array}$ & $\begin{array}{l}\text { Albumim } \\
(\mathrm{g} / \mathrm{dL})\end{array}$ & $\begin{array}{l}\text { PT } \\
(\%)\end{array}$ & $\begin{array}{l}\text { Hb } \\
(\mathrm{g} / \mathrm{dL})\end{array}$ & $\begin{array}{l}\text { Ferritin } \\
(\mathrm{ng} / \mathrm{mL})\end{array}$ \\
\hline Case 2 & Baseline & 1.2 & 3.5 & 83.3 & 14.4 & 895 \\
\hline & Onset & 1.6 & 2.8 & 44.3 & 12.8 & 989 \\
\hline & Turning point & 3.0 & 2.0 & 36.2 & 6.4 & 14 \\
\hline & Recovery stage & 2.0 & 2.6 & 64.3 & 10.4 & 12 \\
\hline Case 3 & Baseline & 1.3 & 3.2 & 40.4 & 15.8 & 569 \\
\hline & Onset & 11.9 & 2.6 & 30.1 & 6.3 & 1210 \\
\hline & Turning point & 2.1 & 2.0 & 21.2 & 11.5 & 543 \\
\hline & Recovery stage & 1.4 & 3.5 & 62.3 & 13.4 & 247 \\
\hline & 4 Ms post recovery & 0.7 & 4.6 & 72.0 & 15.4 & 31 \\
\hline
\end{tabular}

Turning point in the study was designated as the time when improved protein synthesis was detected on laboratory tests. This was after 3 months of treatments with penicillamine in Case 2, while it was after 10 months of treatments in Case 3. The turning point was also associated with changes in iron parameters. Therefore, we postulate that the effect of penicillamine may have been positively modified by GI bleeding resistant to $\mathrm{H}_{2}$ blocker in these cases. Remarkable reduction of $\mathrm{Hb}$ and ferritin in Case 2 suggested that GI bleeding had stopped before the turning point, whereas GI bleeding was still active at the turning point in Case 3, followed by persistent consumption of stored iron. Hemolysis may have been involved at the onset of Case 3, but may be unlikely during other stages of Cases 2 and 3 because triple signs comprising fall in $\mathrm{Hb}$ and increases in bilirubin and ferritin were absent.

Japanese patients $(14,16)$. Based on the wide distribution, homozygotes of the common mutations were found both in consanguineous and non-consanguineous families in central Japan. In addition to the 5 mutations reported previously in our patients, we identified a new mutation with frameshift. There were no apparent phenotype-genotype correlations in the patients with domestic mutations in central Japan.

The hepatic form was found in $22(73.3 \%)$, while the neurological form was found in $5(16.7 \%)$ of the 30 patients in central Japan. ATP7B is an essential transporter for excess copper from the liver into the biliary tract. Therefore, the liver may be a primary target organ, and the extrapyramidal system and other organs may be affected at a later stage of copper toxicosis (5). The sequence of hepatic disorders followed by neurological problems may be present at different ages of diagnosis $(13 \pm 5$ vs. $22 \pm 9)$. There were 2 subtypes of the neurological form. One appeared after noncompliance with copper chelating agents, the other initially presented with the neurological form because an appropriate differential diagnosis of biochemical liver damage was not previously established. Considering the fact that there is no neurological WD without liver disease $(5,6)$, ATP7B analysis may be highly recommended for patients with hepatitis of unknown etiology. Gene analysis could provide a definitive diagnosis of WD in questionable cases, so the neurological form might be recognized as the hepatic form or presymptomatic form with proper testing in these same patients.

The current study demonstrated at least 2 aspects of postgene diagnosis patient management. Acute-onset hepatic failure is not only one of the first manifestations of WD, but also a sequela after diagnosis for patients showing poor compliance or interruption of copper chelating agents. In the present post-gene diagnosis follow-up study, 3 patients were affected by acute hepatic failure. One female patient died from hepatic failure after taking hepatotoxic steroid hormones for fertilization treatment. Severe coagulopathy was associated with progressive encephalopathy, a complication that was generally lethal in WD. Liver transplantation was indicated, but not performed for lack of a donor. In the other 2 male patients presenting with acute hepatic failure without encephalopathy, predicting which patients might benefit from life-saving transplantation was difficult. Our experience supports the reliability of using King's Score for liver transplantation in acute hepatic failure in encephalopathy-free WD (8). The 2 male patients with low index scores for transplantation survived despite suddenonset, prolonged hypoproteinemia without encephalopathy. A 5-year interruption of penicillamine in one patient, and an insufficient dose of penicillamine and abrupt complication by type 1 diabetes mellitus in the other patient could have been triggers that promoted recurrence of hepatic damage, respectively. Turning points in these cases of prolonged hepatic damage were noted in both male patients when GI bleeding followed by iron-deficiency occurred. Further study is needed to determine whether GI bleeding or iron deficiency might positively modify the effect of copper chelators in patients with WD (19).

We lost an additional 2 patients due to suicide in the post diagnosis period. The fact that some patients with WD may be affected by psychiatric problems might explain our follow-up study results. One of these patients was affected by severe dystonia and repeated episodes of depression. Severe neurological complication could be a trigger of suicide in the neuro-psychiatric patient. Unfortunately, we were not able to identify clinical correlates suggestive of the development of suicidal behavior in the other patient. In a recent series of 142 patients with WD, Svetel et al reported suicide in 4 of 30 patients who died during the post-diagnosis treatment period (24). Regarding the long-term management of 
patients with WD, suicide is not a local problem in central Japan, but a worldwide concern. Physicians treating WD patients should be aware of the risk of suicide without prodromal signs, and large scale surveillance and prevention guidelines regarding suicide by patients with WD are needed.

ATP7B gene analysis provides a definitive diagnosis and opportunity to appropriately treat primary copper toxicosis in the liver. The fact that there were older patients with ad- vanced liver failure or late manifestation of the neurological form indicates the need for wider application of definitive diagnostic testing to diagnose patients with early signs of the hepatic form. At gene diagnosis, adequate education regarding compliance in order to avoid recurrence of severe hepatic failure as well as emotional care to prevent suicide are needed in the long-term management of patients with WD.

\section{References}

1. Kinnier Wilson SA. Progressive lenticular degeneration: a familiar nervous disease associated with cirrhosis of the liver. Brain 34: 295-507, 1912.

2. Walshe JM. New oral therapy. Lancet 1: 25-26, 1956.

3. Walshe JM. Management of penicillamine nephropathy in Wilson's disease: a new chelating agent. Lancet 2: 1401-1402, 1969.

4. Brewer GJ, Hill GM, Prasad AS, Cossack ZT, Rabbani P. Oral zinc therapy for Wilson's disease. Ann Intern Med 99: 314-319, 1983.

5. Roberts EA, Schilsky ML. A practice guideline on Wilson disease. Hepatology 37: 1475-1492, 2003.

6. Gitlin JD. Wilson disease. Gastroenterology 125: 1868-1877, 2003.

7. Asonuma K, Inomata $\mathrm{Y}$, Kasahara M, et al. Living related liver transplantation from heterozygote genetic carriers to children with Wilson's disease. Pediatr Transplant 3: 201-205, 1999.

8. Dhawan A, Taylor RM, Cheeseman P, De Silva P, Katsiyiannakis L, Mieli-Vergani G. Wilson disease in children: 37-year experience and revised King's score for liver transplantation. Liver Transpl 11: 441-448, 2005.

9. Tanzi RE, Petrukhin K, Chernov I, et al. The Wilson disease gene is a copper transporting ATPase with homology to the Menkes disease gene. Nat Genet 5: 344-350, 1993.

10. Bull PC, Thomas GR, Rommens JM, Forbes JR, Cox DW. The Wilson disease gene is a putative copper transporting P-type ATPase similar to the Menkes gene. Nat Genet 5: 327-337, 1993.

11. Yamaguchi Y, Heiny ME, Gitlin JD. Isolation and characterization of a human liver cDNA as a candidate gene for Wilson disease. Biochem Biophys Res Commun 197: 271-277, 1993.

12. Shimizu N, Kawase C, Nakazono H, Shimatake H, Aoki T. A novel RNA splicing mutation in Japanese patients with Wilson disease. Biochem Biophys Res Commun 217: 16-20, 1995.

13. Thomas GR, Forbes JR, Roberts EA, Walshe JM, Cox DW. The Wilson disease gene: spectrum of mutations and their consequences. Nat Genet 9: 210-217, 1995.

14. Nanji MS, Nguyen VT, Kawasoe JH, et al. Haplotype and muta- tion analysis in Japanese patients with Wilson disease. Am J Hum Genet 60: 1423-1429, 1997.

15. Shah AB, Chernov I, Zhang HT, et al. Identification and analysis of mutations in the Wilson disease gene (TP7B): population frequencies, genotype-phenotype correlation, and functional analyses. Am J Hum Genet 61: 317-328, 1997.

16. Yamaguchi A, Matsuura A, Arashima S, Kikuchi Y, Kikuchi K. Mutations of ATP7B gene in Wilson disease in Japan: identification of nine mutations and lack of clear founder effect in a Japanese population. Hum Mutat Suppl 1: S320-S322, 1998.

17. Shimizu N, Nakazono H, Takeshita $Y$, et al. Molecular analysis and diagnosis in Japanese patients with Wilson's disease. Pediatr Int 41: 409-413, 1999.

18. Okada T, Shiono Y, Hayashi H, et al. Mutational analysis of ATP7 B and genotype-phenotype correlation in Japanese with Wilson's disease. Hum Mutat 15: 454-462, 2000.

19. Shiono $\mathrm{Y}$, Wakusawa $\mathrm{S}$, Hayashi $\mathrm{H}$, et al. Iron accumulation in the liver of male patients with Wilson's disease. Am J Gastroenterol 96: 3147-3151, 2001.

20. Ferenci P, Caca K, Loudianos G, et al. Diagnosis and phenotypic classification of Wilson disease. Liver Int 23: 139-142, 2003.

21. Monteleone G, Del Vecchio Blanco G, Monteleone I, et al. Posttranscriptional regulation of Smad7 in the gut of patients with inflammatory bowel disease. Gastroenterology 129: 1420-1429, 2005.

22. Muller T, van de Sluis B, Zhernakova A, et al. The canine copper toxicosis gene MURR1 does not cause non-Wilsonian hepatic copper toxicosis. J Hepatol 38: 164-168, 2003.

23. Camaschella C, Roetto A, Cali A, et al. The gene TFR2 is mutated in a new type of haemochromatosis mapping to $7 \mathrm{q} 22$. Nat Genet 25: 14-15, 2000.

24. Svetel M, Pekmezovic T, Petrovic I, et al. Long-term outcome in Serbian patients with Wilson disease. Eur J Neurol 16: 852-857, 2009.

(C) 2010 The Japanese Society of Internal Medicine http://www.naika.or.jp/imindex.html 